\title{
Arabic Script based Digit Recognition Systems
}

\author{
Saeeda Naz ${ }^{1}$, Saad B. Ahmed ${ }^{2}$, Riaz Ahmad ${ }^{3}$, Muhammad I. Razzak ${ }^{2}$ \\ 1. GGPGC No. 1, Higher Education Department, KPK, Pakistan \\ 2. King Saud Bin Abdul Aziz University for Health Sciences, Riyadh, Saudi Arabia \\ 3. University of Technology, Kaiserslautern, Germany \\ (Saeedanaz292, isaadahmed, riaz77, mirpak)@gmail.com
}

\begin{abstract}
There are a lot of intensive research on character and numeral recognition for some of popular scripts such as Roman, Arabic, Persian/Farsi, Chinese and Indian. Unfortunately, there is less work on the Urdu language which is used by $1 / 4$ population of the world. In this paper we present a review on numeral recognition for Urdu, Arabic and Farsi. Most of the published paper for Urdu language since 2003 and recent publications in the Arabic and Farsi languages have been summarized in this survey paper. The Unicode system and writing glyph of digits have been analyzed in Arabic language and its derivative languages. We also added some future direction of research on numeral recognition system.
\end{abstract}

Keywords: Digit Recognition, Arabic Script, Unicode System

\section{Introduction}

An intensive research is being recorded in the field of Optical Character Recognition (OCR) in the last decades. The objective of OCR is the conversion of images of characters, digits, and special symbols into editable text form that can be searchable, changeable, and transferable through internet; and required less storage memory.

There are a lot of work on Arabic OCR and Farsi since 1970s [1], [2] but the Urdu character recognition has got attention of researcher in the 2000s [3]. First work on Urdu OCR system was published in 2000 [3] and a tentative Urdu character recognition system has made available in the 2014s [4] that has some limitation like just upload jpeg image, 300 DPI etc. but it is a good and pioneer attempt for Urdu OCR. The first comprehensive literature review for Urdu OCR has been published in 2013 [5] that bring into light the researchers' efforts and challenges in Urdu OCR development since 2000s. This survey presents some unique issues related to Nasta'liq writing style and benefits to the new reader and researchers in the field of Urdu OCR.

In particular, Urdu digit recognition is more complicated than Latin language because Urdu numerals have more similarity among digits, for example just angle is changed in digits $7(r)$ and $8(1)$.The researchers face problems during process of recognition due to same shape, curves, holes and different writing styles so on.

Many approaches and methods have been presented for Arabic and Farsi digit recognition and researchers have come up with few approaches for the Urdu digit recognition. However, there is still a cry for efficient and improved digit recognition system for Arabic, Farsi and Urdu. In this survey paper, many of recent and important work for Arabic and Farsi have been surveyed and in more detail the work for Urdu has been presented because this is first review paper for Urdu digit recognition. Apart from that, peculiarities and issues are also discussed.

\section{Comparisons and Peculiarities}

In the Arabic script, the languages like Arabic, Farsi, Urdu, Pashto, Sindhi, Kurdish and Uighur are cursive and context sensitive based languages. The characters are written from right to left but the digits/numbers are written from left to right. The characters have the property of joiner and non-joiner that imposes two to four shapes for characters depending on its position/context in the ligature/subword. The numbers/digits are free from the number of shapes regarding position. Shapes of numbers are varying with language. The two sets of Unicode are introduced for numerals in the Arabic script based languages. The Unicode series"U+0660 - U+0669" are for Arabic-Indic digits and "U+06F0 - U+06F" is for Eastern Arabic-Indic digits for derivate languages from Arabic script. The Unicode and the glyphs of Eastern Arabic-Indic digits with its variants are shown in the Table. 1. for Arabic, Farsi and Urdu [6]. 
Table 1. The Unicode and the glyphs of digits in each language.

\begin{tabular}{|c|c|c|c|c|c|c|c|c|c|c|}
\hline Western Arabic & $\mathbf{O}$ & 1 & 2 & 3 & 4 & 5 & 6 & 7 & 8 & 9 \\
\hline $\begin{array}{l}\text { Eastern Arabic/ } \\
\text { Arabic-Indic } \\
\text { digits } \\
\text { Unicode }\end{array}$ & $\begin{array}{l}\bullet \\
u+ \\
0660\end{array}$ & $\begin{array}{c}\text { I } \\
u+ \\
0661\end{array}$ & $\begin{array}{l}Y \\
u+ \\
0662\end{array}$ & $\begin{array}{l}\text { r } \\
u+ \\
0663\end{array}$ & $\begin{array}{l}\Sigma \\
u+ \\
0664\end{array}$ & $\begin{array}{c}0 \\
u+ \\
0665\end{array}$ & $\begin{array}{c}7 \\
u+ \\
0666\end{array}$ & $\begin{array}{l}V \\
U+ \\
0667\end{array}$ & $\begin{array}{l}\text { 人 } \\
u+ \\
0668\end{array}$ & $\begin{array}{l}q \\
u+ \\
066 \\
9\end{array}$ \\
\hline $\begin{array}{l}\text { Perso-Arabic } \\
\text { Variant/Eastern } \\
\text { Arabic-Indic } \\
\text { digits } \\
\text { Unicode }\end{array}$ & $\begin{array}{l}\bullet \\
u+ \\
\text { O6Fo }\end{array}$ & $\begin{array}{c}1 \\
u+ \\
\text { O6F1 }\end{array}$ & $\begin{array}{l}Y \\
u+ \\
\text { O6F2 }\end{array}$ & $\begin{array}{c}\text { r } \\
u+ \\
\text { o6f3 }\end{array}$ & $\begin{array}{l}P \\
u+ \\
\text { O6F4 }\end{array}$ & $\begin{array}{l}\Delta \\
u+ \\
06 F 5\end{array}$ & $\begin{array}{l}9 \\
u+ \\
06 F 6\end{array}$ & $\begin{array}{l}V \\
U+ \\
\text { O6F7 }\end{array}$ & $\begin{array}{l}\text { 人 } \\
u+ \\
\text { o6F8 }\end{array}$ & $\begin{array}{l}q \\
u+ \\
06 F \\
9\end{array}$ \\
\hline $\begin{array}{l}\text { Perso-Arabic } \\
\text { Urdu Variant } \\
\text { Unicode }\end{array}$ & $\begin{array}{c}\overrightarrow{u+} \\
06 F 0\end{array}$ & $\underset{06 F 1}{u^{\prime}+}$ & $\underset{06 F 2}{\stackrel{u}{u+}}$ & $\underset{\substack{u+\\
\mathrm{U}+}}{\mathrm{N} 3 \mathrm{F3}}$ & $\underset{\text { O6F4 }}{\stackrel{C}{U}+}$ & $\underset{\substack{U+\\
\text { O6F5 }}}{\boldsymbol{\omega}}$ & $\begin{array}{c}y \\
u+ \\
06 F 6\end{array}$ & $\underset{\substack{u+\\
\text { 06F7 }}}{L^{u}}$ & $\widehat{N}_{06 \mathrm{~F} 8}$ & $\begin{array}{c}9 \\
u^{+}+ \\
06 F \\
9\end{array}$ \\
\hline
\end{tabular}

There is the comparison of the numerals among the Arabic script's languages:

- The digits 4, 5, and 6 in Farsi are differing than Arabic as shown in Table 1.

- The glyph of digit $4\left({ }^{\leftarrow}\right)$ in Urdu and Sindhi is different from glyph of digit $4\left(^{\leftarrow}\right)$ in Farsi.

- The glyph of digit $5(\Delta)$ is similar in Urdu, Farsi and Sindhi; and different than glyph of digits $5\left({ }^{\circ}\right)$ in Arabic.

- The glyph of $6\left(^{8}\right)$ in Urdu is different than glyph of digit $6\left({ }^{9}\right)$ in Farsi and glyph of digit 6 (7) in Arabic.

- The glyph of digit $7\left({ }^{\vee}\right)$ in Urdu and Sindhi are different than glyph of digit $7\left({ }^{\vee}\right)$ in Farsi and Arabic.

The Eastern Arabic-Indic numerals are misclassified and not recognized properly due to:

- Similar structures of digits.

- Touch or overlap of one digit with another digit.

- Sometimes a digit confuses with other digit by model or system and recognizes wrongly.

- Not written properly in handwritten case.

- The digit 0 in handwritten Arabic mixes up with 5.

- The digits 5 and 0 also create ambiguity with isolated character of "Hey" (०).

\section{Literature Survey}

This study focuses on survey of numerals/digits classification and recognition for Urdu, Farsi and then Arabic with their state of the art techniques.

\subsection{Urdu Digit Recognition}

The Urdu language is derivate form of Farsi language and Farsi language itself is an extended language of Arabic script. Urdu digits share the Unicode of Farsi but some glyphs for numerals are changed from the Farsi. In this section, we survey the state of the art techniques for the Urdu numeral recognition.

Pal and Sarkar [7] used two stages classification and recognition system for isolated Urdu digits. In the first stage, the topological features and contour features used for classification of digits using CART tree classifier and then water reservoir features were used for recognition for similar and confused digits at leaf node of the tree in the second stage. Shamsher et al.[8]applied machine learning model like FFNN on features like top, left, right, and bottom extreme pixels of printed Urdu digits. But the dataset's size of digits has not written and no separate accuracy has shown for digits. Another effort found in [9], the feature extraction and correlation applied for both handwritten and printed Urdu numerals and achieved $93 \%$ and $76 \%$ respectively.

An attempt on the Urdu isolated handwritten digits was carried by Sagheer et al. [10]. They first developed the dataset and then binarized, de-noise, and normalize the images of digits. The dataset is divided into 47, 151 training samples and 13,178 testing sample for training and testing SVM on Gradient features. The dataset is not free of cost.

Basu et al. [11] presented recognition system for postal address code for Latin, Devanagari, Bangla and Urdu. Hough transform is used for localization and isolation. Then digits from 4 scripts are clustered into 25 group and extracted multiple features like Quad Tree Longest Run (QTLR), overlapping longest-run (OLR), directional chain-code histogram $(\mathrm{CCH})$ and Gabor filter based features, shadow features [29], shadow-longest run-octant centroid (SLOC) and combinations of shadow- longest run (SLR). The 
dataset of Urdu is divided into 2000 training set and 1000 testing set and trained MLP and SVM. The best result achieved with QTLP features and SVM.

In [12], Haider and Yousaf developed descriptor coinntaing the shape context and then computed bending energy (BE) to measure the difference between the training and testing sets. In [13], the extension of the [12] work is presented. In which author reported a gradual pruning approach for faster processing that computed the differences between training and testing sets.

Razzak et al. [14] performed binarization, skew and slant correction, and normalization in the offline domain. They performed experiment on HMM, Fuzzy logic rules and combination of both using structural features like holes, start and end point of the chain code, right, left, up and down direction of the pixel in a digits, number of strokes, number and position of cusp etc. for online Urdu and Arabic digit recognition.

Malik et al. [15] used structural features and tree based dictionary for online isolated Urdu digits.

Table 2. Urdu Numeral Recognition.

\begin{tabular}{|c|c|c|c|c|c|}
\hline Authors & Language & Features & Classification & Dataset & $\begin{array}{l}\text { Accur } \\
\text { acy } \\
(\%)\end{array}$ \\
\hline $\begin{array}{l}\text { Pal. and } \\
\text { Sarkar } \\
2003\end{array}$ & $\begin{array}{l}\text { Printed } \\
\text { Urdu } \\
\text { Digits }\end{array}$ & $\begin{array}{l}\text { Number of } \\
\text { holes, position } \\
\text { of holes from } \\
\text { the bounding } \\
\text { box, number } \\
\text { of components } \\
\text { in a digit, } \\
\text { contour and } \\
\text { water reserver }\end{array}$ & CART & ---- & 97.8 \\
\hline $\begin{array}{l}\text { Shamsher } \\
\text { et al. }\end{array}$ & $\begin{array}{l}\text { Printed } \\
\text { Urdu } \\
\text { Digits }\end{array}$ & Statistical & FFNW & $\begin{array}{l}---- \\
\end{array}$ & 98.3 \\
\hline $\begin{array}{l}\text { Bilal et } \\
\text { al. } 2012\end{array}$ & $\begin{array}{l}\text { Printed } \\
\text { and } \\
\text { Handwritt } \\
\text { en Urdu } \\
\text { Digits }\end{array}$ & $\begin{array}{l}\text { Features } \\
\text { Template }\end{array}$ & $\begin{array}{l}\text { Matching } \\
\text { Correlation }\end{array}$ & $\begin{array}{l}---- \\
100\end{array}$ & $\begin{array}{l}93 \\
76\end{array}$ \\
\hline $\begin{array}{l}\text { Sagheer } \\
\text { et al. } \\
2009\end{array}$ & $\begin{array}{l}\text { Handwritt } \\
\text { en Urdu } \\
\text { Digits }\end{array}$ & Gradient & SVM & 60,000 & 98.61 \\
\hline $\begin{array}{l}\text { Basu et } \\
\text { al. } 2010\end{array}$ & $\begin{array}{l}\text { Handwritt } \\
\text { en Urdu } \\
\text { Digits }\end{array}$ & $\begin{array}{l}\text { QTLR } \\
\text { OLR } \\
\text { Shadow } \\
\text { SLR } \\
\text { SLOC } \\
\text { Gabor } \\
\text { CCH } \\
\\
\text { QTLR } \\
\text { OLR } \\
\text { Shadow } \\
\text { SLR } \\
\text { SLOC } \\
\text { Gabor } \\
\text { CCH }\end{array}$ & MLP & 3,000 & $\begin{array}{l}96.2 \\
93.80 \\
91.09 \\
93.70 \\
94.80 \\
95.10 \\
91.30 \\
\\
95.60 \\
94.10 \\
90.60 \\
94.20 \\
94.80 \\
94.90 \\
90.60\end{array}$ \\
\hline $\begin{array}{l}\text { Haider } \\
2004\end{array}$ & $\begin{array}{l}\text { Handwritt } \\
\text { en Urdu } \\
\text { Digits }\end{array}$ & Shape context & $\begin{array}{l}\text { Bending energy } \\
\text { Bipartite graph } \\
\text { matching }\end{array}$ & 40 & -- \\
\hline $\begin{array}{l}\text { Haider } \\
\text { and } \\
\text { Yusuf } \\
2000\end{array}$ & $\begin{array}{l}\text { Handwritt } \\
\text { en Urdu } \\
\text { Digits }\end{array}$ & Shape context & $\begin{array}{l}\text { bending energy } \\
\text { Bipartite Graph } \\
\text { matching \& } \\
\text { Inter Object } \\
\text { Distance }\end{array}$ & 40 & 92.6 \\
\hline $\begin{array}{l}\text { Razzak et } \\
\text { al. } 2009\end{array}$ & $\begin{array}{l}\text { Online } \\
\text { Urdu } \\
\text { Digits }\end{array}$ & structural & $\begin{array}{l}\text { fuzzy rule } \\
\text { HMM } \\
\text { Hybrid }\end{array}$ & 900 & $\begin{array}{l}97.4 \\
96.2 \\
97.8\end{array}$ \\
\hline $\begin{array}{l}\text { Malik et } \\
\text { al. } 2005\end{array}$ & $\begin{array}{l}\text { Online } \\
\text { Urdu } \\
\text { Digits }\end{array}$ & Structural & $\begin{array}{l}\text { Structural Tree } \\
\text { Based } \\
\text { Dictionary }\end{array}$ & ----- & 93 \\
\hline
\end{tabular}

\subsection{Arabic/Farsi Digit Recognition}

In the literature, we found some efforts on Arabic and Farsi digit recognition but the work is not matured as the Latin digit recognition. Still there is a room for researcher to work for achieving the best digit recognition system. In this section, we try to present the most important and recent work in these two languages.

Azad et al. [16] reported handwritten Farsi digit recognition on features such as transit, angel and distance of contour pixels and trained KNN. Another effort found by Salimi and Giveki [17], in which PCA and 2DPCA Ensemble is used on singular value decomposition (SVD). In 2013, Rawdan [18] presented a novel method of centroid distance combination of Rough sets and Artificial Neural Network (RS_RNN) for Arabic/Farsi isolated numeral recognition. Author employed the hybrid model on IFHCBD database and got accuracy upto 93\%.Shokoohi et al [19] perform experiment of CNN on features extracted using nonlinear algorithm from CENPARMI Farsi dataset. They reported $78 \%$ recognition rate.

Alvarie [20] extracted geometric features and trained a decision tree based classifier. In 2013, MLP and SVM are implemented on databases of MNIST, HODA, IFHCDB and BANGLA by Azmi [21]. They extracted total nine features from triangular geometry shape; in which six were taken from the coordinated of the triangle and three form the angles. In [22], extended version of [21] reported and merged the supervised learning such as Euclidean Distance method is for retrieval of information; and Majority Voting and Mean Average Precision is for classification on the features those extracted in the [21]. Nooraliei [23] presented SVM model for handwritten Farsi numeral recognition. The zoning and projection histogram features extracted and fed to SVM for classification and recognition. The recognition rate achieved upto 97.83\%.Other Farsi digit recognition systems reported in [24]. Authors extracted twenty templates form the normalized images of digits and NN-MLP employed for classification. The $97.65 \%$ accuracy reported.

In 2008, Liu and Suen [25] demonstrated six classifiers (MLP neural network, modified quadratic discriminant function (MQDF), discriminative learning quadratic discriminant function (DLQDF), polynomial network classifier (PNC), class-specific feature polynomial classifier (CFPC), and one-versus-all SVM classifier) for both Indian and Arabic handwritten printed numerals (Bangla and Farsi) on databases of ISI Bangla numerals, CENPARMI Farsi numerals (1800) and IFHCDB Farsi numerals (17,740). The gradient direction histogram features were extracted. 
The SVM gave the highest accuracy of $99.16 \%$ and $99.7 \%$ on the databases, respectively.

Behbahan [26] has extracted the directional features from each image of Farsi digits and used BPNN for isolated printed Farsi digits. In 2010,Boveiri et al. [27] used geometric moment invariant for training fuzzy min-max neural networks. Another work by same author reported in[28] that computed on minimum mean distance and other two models of Nearest Neighbor Rule and MLP on extended moment invariant features with statistical features.

In 2011, Rashnoodi et al [29][30] presented another approach for the recognition of Farsi handwritten digits with the dataset of 80,000 samples. The binarization, slant correction, thickening and size normalization were performed in the pre-processing stage. Then average angle and distance pixels features were extracted by using the box approach. Finally, support vector machine (SVM) with linear kernel is used for classification and resulted features achieved 98.94\% recognition rate. Another work by Rashnoodi et al. [31] in 2012 presented support vector machine (SVM), K-nearest neighbor (K-NN) and sequential minimal optimization (SMO) using features of central moments, covariance, median and variance. The principle component analysis applied for recognition of Farsi handwritten digits. The experiment was conducted on database consisting of 1699 handwritten Farsi digit images and $92.38 \%$ higher recognition rate was achieved by SMO than the other two classifiers. The SVM classifier achieved $91.34 \%$ and K-nearest neighbor classifier achieved $92.04 \%$ recognition rate.

Ghanbari [32] extracted zonal features and then they used fuzzy method for recognition and for better accuracy RPSO algorithm was used for selection the best group for fuzzy method.

In 2014, Roy et al. [33] performed experiments of Indian languages with Arabic for handwritten numeral recognition and proposed Axiomatic Fuzzy Set (AFS) theory for feature selection. In this paper[34], different kind of features like Fourier switch features, stroke density features, contour features, projection features, the barycenter and barycenter distance feature were extracted from handwritten Arabic digits and then filter the features using under and outer analogy.

Recently in 2014, Ghaleb et al. [35] calculated density of digits through horizontal and vertical centroid moments and then used minimum distance classifier. Mahmoud [36] reported Gabor-based filters and Support vector machine (SVM) and achieved highest two average recognition rates are $99.85 \%$ and $97.94 \%$ obtained by using 3 scales and 5 orientation and 4 scale and 5 orientations. The same authors put forward HMM and nearest neighbor classifier with generation of angle, distance, horizontal and vertical span features for recognition of independent writer offline handwritten Arabic numeral in [37]. They used HMM and the nearest neighbor classifiers, respectively. The misclassification was nearly $1 \%$ in the case of HMM.

In [38], Sinha and Kumar extracted zoning based features like image centroid, zone centroid and combination of these two centroids and passed the extracted features vector to SVM classifier. The highest recognition rate was achieved upto $97.71 \%$ for the hybrid features. Sabri and Awaida [39] segmented the images of digits into segments and extracted features like structural, gradient and concavity. They implemented SVM and HMM on extracted features and also compare the result achieved on different features set..The maximum recognition rates were 99.83\% for SVM and $99.00 \%$ for HMM.

Awaidah and Mahmoud [40], presented scale invariant and translation invariant technique HMM classifiers for off-line handwritten Arabic numerals recognition with multi-resolution feature extraction approach using GSC algorithm. The features were edge curvature in a neighborhood of a pixel, short strokes types which span several pixels and certain concavities which can span across the image. Different grid sizes have used for segmentation of an image.

Ahmad and Maen [41] represented a structural online approach for the Arabic digits recognition. The shape based features are used by extracting the primary and secondary primitives by identifying the changes in the slope sign, and then the matching has been done by using the special grammar by matching the string of primitives to the digit.

Das et al. [42] combined PCA/MPCA (Principal Component Analysis/Modular PCA) and QTLR (Quad-tree based hierarchically derived LongestRun) for extraction of features handwritten numerals of Arabic and other four scripts using SVM classifier on database of CMATER db 3.4.1 consisting of 3000 samples. Other effort found for Arabic digit recognition found in [43].

All the methods for feature extraction and state of the art techniques for classification for Arabic and Farsi are summarized into table 3. 
Table 3. Farsi/Arabic Numeral Recognition.

\begin{tabular}{|c|c|c|c|c|c|}
\hline Authors & $\begin{array}{l}\text { Langua } \\
\text { ge }\end{array}$ & Features & Classification & Dataset & $\begin{array}{l}\text { Accur } \\
\text { acy } \\
(\%)\end{array}$ \\
\hline $\begin{array}{l}\text { Azad et } \\
\text { al. } \\
2013\end{array}$ & $\begin{array}{l}\text { Handw } \\
\text { ritten } \\
\text { Farsi }\end{array}$ & $\begin{array}{l}\text { Transit, angel } \\
\text { and distance of } \\
\text { contour pixels }\end{array}$ & KNN & 20,000 & 99.82 \\
\hline $\begin{array}{l}\text { Salimia } \\
\text { nd } \\
\text { Giveki } \\
2013\end{array}$ & $\begin{array}{l}\text { Handw } \\
\text { ritten } \\
\text { Farsi }\end{array}$ & $\begin{array}{l}\text { PCA and } \\
\text { 2DPCA }\end{array}$ & $\begin{array}{l}\text { Ensemble. } \\
\text { singular } \\
\text { value } \\
\text { decompositio } \\
\mathrm{n} \text { (SVD) }\end{array}$ & 6000 & $\begin{array}{l}97.02 \\
- \\
97.30\end{array}$ \\
\hline $\begin{array}{l}\text { Radwa } \\
\text { n } 2013\end{array}$ & $\begin{array}{l}\text { Handw } \\
\text { ritten } \\
\text { Farsi }\end{array}$ & $\begin{array}{l}\text { Centroid } \\
\text { distance }\end{array}$ & $\begin{array}{l}\text { Back } \\
\text { propagation } \\
\text { RNNS }\end{array}$ & 181 & 93 \\
\hline $\begin{array}{l}\text { Shokoo } \\
\text { hi } 2013\end{array}$ & $\begin{array}{l}\text { Handw } \\
\text { ritten } \\
\text { Farsi }\end{array}$ & $\begin{array}{l}\text { Non-Linear } \\
\text { algorithm }\end{array}$ & $\mathrm{CNN}$ & 18000 & --- \\
\hline $\begin{array}{l}\text { Liua } \\
2008\end{array}$ & $\begin{array}{l}\text { Handw } \\
\text { ritten } \\
\text { Farsi }\end{array}$ & $\begin{array}{l}\text { Gradient } \\
\text { direction } \\
\text { histogram }\end{array}$ & $\begin{array}{l}\text { MPL } \\
\text { MQDF } \\
\text { DLQDF } \\
\text { PNC } \\
\text { CFPC } \\
\text { SVM } \\
\text { MLP } \\
\text { MQDF } \\
\text { DLQDF } \\
\text { PNC } \\
\text { CFPC } \\
\text { SVM }\end{array}$ & 17,740 & $\begin{array}{l}98.47 \\
98.06 \\
98.86 \\
98.88 \\
98.90 \\
98.94 \\
99.42 \\
99.52 \\
99.64 \\
99.59 \\
99.60 \\
99.63\end{array}$ \\
\hline $\begin{array}{l}\text { Ghanb } \\
\text { ari et } \\
\text { al. } \\
2012\end{array}$ & $\begin{array}{l}\text { Handw } \\
\text { ritten } \\
\text { Farsi } \\
\text { digits }\end{array}$ & Zoning & $\begin{array}{l}\text { Fuzzy, } \\
\text { Binary } \\
\text { Particle } \\
\text { Swarm } \\
\text { Optimization } \\
\text { (BPSO) } \\
\text { algorithm } \\
\text { and Binary } \\
\text { Genetic } \\
\text { Algorithm } \\
\text { (BGA) } \\
\end{array}$ & 80,000 & $\begin{array}{l}80.19 \\
- \\
89.65\end{array}$ \\
\hline $\begin{array}{l}\text { Behbah } \\
\text { an et } \\
\text { al. }\end{array}$ & $\begin{array}{l}\text { Handw } \\
\text { ritten } \\
\text { Farsi } \\
\text { digits } \\
\end{array}$ & Pixels & BPNN & HODA & 98.18 \\
\hline $\begin{array}{l}\text { Boveiri } \\
2010\end{array}$ & $\begin{array}{l}\text { Printed } \\
\text { Farsi } \\
\text { digits }\end{array}$ & $\begin{array}{l}\text { Geometric } \\
\text { moment } \\
\text { invariant }\end{array}$ & $\begin{array}{l}\text { Fuzzy min- } \\
\text { max neural } \\
\text { networks }\end{array}$ & 400 & 99.16 \\
\hline $\begin{array}{l}\text { Boveiri } \\
2010 a\end{array}$ & $\begin{array}{l}\text { Printed } \\
\text { Farsi } \\
\text { digits }\end{array}$ & $\begin{array}{l}\text { extended } \\
\text { moment } \\
\text { invariant with } \\
\text { statistical }\end{array}$ & $\begin{array}{l}\text { Min Mean } \\
\text { Distance } \\
\text { KNN Rule } \\
\text { MLP }\end{array}$ & 400 & $\begin{array}{l}73.5 \\
96.5 \\
99 \\
\end{array}$ \\
\hline $\begin{array}{l}\text { Alvari } \\
\text { et al. } \\
2013 \\
\end{array}$ & $\begin{array}{l}\text { Handw } \\
\text { ritten } \\
\text { Farsi }\end{array}$ & $\begin{array}{l}\text { geometric } \\
\text { features }\end{array}$ & $\begin{array}{l}\text { Rules base } \\
\text { decision tree }\end{array}$ & 13,620 & $\begin{array}{l}98.67 \\
- \\
99.36 \\
\end{array}$ \\
\hline $\begin{array}{l}\text { Azmi } \\
\text { et al. } \\
2013\end{array}$ & $\begin{array}{l}\text { Handw } \\
\text { ritten } \\
\text { Farsi/ } \\
\text { Arabic } \\
\text { /Jawi }\end{array}$ & $\begin{array}{l}\text { Side and angles } \\
\text { of tiangle like } \\
\text { ratio of } 3 \text { sides, } \\
3 \text { angles and } \\
\text { gradient of } 3 \\
\text { angles }\end{array}$ & $\begin{array}{l}\text { SVM } \\
\text { MLP }\end{array}$ & $\begin{array}{l}\text { HODA } \\
\text { IFHCD } \\
\text { B }\end{array}$ & $\begin{array}{l}98.07 \\
96.73\end{array}$ \\
\hline $\begin{array}{l}\text { Azmi } \\
\text { et al. } \\
2012\end{array}$ & $\begin{array}{l}\text { Handw } \\
\text { ritten } \\
\text { Farsi/ } \\
\text { Arabic } \\
\text { /Jawi }\end{array}$ & $\begin{array}{l}\text { Side and angles } \\
\text { of tiangle like } \\
\text { ratio of } 3 \text { sides, } \\
3 \text { angles and } \\
\text { gradient of } 3 \\
\text { angles }\end{array}$ & $\begin{array}{l}\text { Majority } \\
\text { Voting } \\
(\mathrm{MV}) \\
\text { Mean } \\
\text { Average } \\
\text { Precision } \\
\text { MAP } \\
\text { MLP }\end{array}$ & 80,000 & $\begin{array}{l}82.78 \\
9 \\
\\
\\
87.67 \\
0\end{array}$ \\
\hline
\end{tabular}

\begin{tabular}{|c|c|c|c|c|c|}
\hline & & & & & 87.05 \\
\hline $\begin{array}{l}\text { Ziaratb } \\
\text { an et } \\
\text { al. } \\
2007\end{array}$ & $\begin{array}{l}\text { Handw } \\
\text { ritten } \\
\text { Farsi/ } \\
\text { Arabic }\end{array}$ & $\begin{array}{l}\text { Zernike based } \\
\text { features }\end{array}$ & $\begin{array}{l}\text { Full search } \\
\text { Template } \\
\text { Matching } \\
\text { heirarical } \\
\text { search } \\
\text { template } \\
\text { matching }\end{array}$ & 10,000 & $\begin{array}{l}97.65 \\
97.59\end{array}$ \\
\hline $\begin{array}{l}\text { Rashno } \\
\text { di } 2011\end{array}$ & $\begin{array}{l}\text { Handw } \\
\text { ritten } \\
\text { Farsi } \\
\end{array}$ & $\begin{array}{l}\text { Angle and } \\
\text { distance in box }\end{array}$ & $\begin{array}{l}\text { SVM with } \\
\text { linear kernal }\end{array}$ & 80,000 & 98.94 \\
\hline $\begin{array}{l}\text { Rashno } \\
\text { di } 2012\end{array}$ & $\begin{array}{l}\text { Handw } \\
\text { ritten } \\
\text { Farsi }\end{array}$ & $\begin{array}{l}\text { Central } \\
\text { moments, } \\
\text { covariance, } \\
\text { median and } \\
\text { variance and } \\
\text { PCA }\end{array}$ & $\begin{array}{l}\text { SMO } \\
\text { SVM } \\
\text { KNN }\end{array}$ & 1600 & $\begin{array}{l}92.38 \\
91.34 \\
92.04\end{array}$ \\
\hline $\begin{array}{l}\text { Roy } \\
2013\end{array}$ & $\begin{array}{l}\text { Handw } \\
\text { ritten } \\
\text { Arabic }\end{array}$ & $\begin{array}{l}\text { Fourier switch } \\
\text { features, stroke } \\
\text { density features, } \\
\text { contour } \\
\text { features, } \\
\text { projection } \\
\text { features, the } \\
\text { barycenter and } \\
\text { barycenter } \\
\text { distance feature }\end{array}$ & --- & --- & --- \\
\hline $\begin{array}{l}\text { Qing et } \\
\text { al. } \\
2013\end{array}$ & $\begin{array}{l}\text { Handw } \\
\text { ritten } \\
\text { Arabic }\end{array}$ & $\begin{array}{l}\text { gradient based } \\
\text { directional and } \\
\text { quad-tree based } \\
\text { longest-run }\end{array}$ & SVM & --- & --- \\
\hline $\begin{array}{l}\text { Ghaleb } \\
\text { et al. } \\
2014\end{array}$ & $\begin{array}{l}\text { Printed } \\
\text { Arabic } \\
\\
\text { Handw } \\
\text { ritten } \\
\text { Arabic }\end{array}$ & $\begin{array}{l}\text { Horizontal and } \\
\text { vertical } \\
\text { moments }\end{array}$ & $\begin{array}{l}\text { Mininmum } \\
\text { distance } \\
\text { classifier }\end{array}$ & $\begin{array}{l}198(22 \\
\text { for each } \\
\text { digit in } \\
1-9) \\
4500(50 \\
0 \text { for } \\
\text { each } \\
\text { digit })\end{array}$ & 74.93 \\
\hline $\begin{array}{l}\text { Mehm } \\
\text { oud } \\
2008 \\
\end{array}$ & $\begin{array}{l}\text { Handw } \\
\text { ritten } \\
\text { Arabic } \\
\end{array}$ & Gabor & SVM & 21,120 & 99.85 \\
\hline $\begin{array}{l}\text { Mehm } \\
\text { oud } \\
2008\end{array}$ & $\begin{array}{l}\text { Handw } \\
\text { ritten } \\
\text { Arabic }\end{array}$ & $\begin{array}{l}\text { angle span, } \\
\text { distance span, } \\
\text { horizontal and } \\
\text { vertical span }\end{array}$ & $\begin{array}{l}\text { HMM } \\
\text { NNC }\end{array}$ & 21,120 & $\begin{array}{l}97,99 \\
94.35\end{array}$ \\
\hline $\begin{array}{l}\text { Sabri } \\
2010\end{array}$ & $\begin{array}{l}\text { Handw } \\
\text { ritten } \\
\text { Arabic } \\
\end{array}$ & $\begin{array}{l}\text { edge curvature, } \\
\text { short stroke \& } \\
\text { concavities }\end{array}$ & $\begin{array}{l}\text { SVM } \\
\text { HMM }\end{array}$ & 21,120 & $\begin{array}{l}99.83 \\
90.0\end{array}$ \\
\hline $\begin{array}{l}\text { Sinha } \\
\text { and } \\
\text { Kumar } \\
2013\end{array}$ & $\begin{array}{l}\text { Handw } \\
\text { ritten } \\
\text { Arabic }\end{array}$ & $\begin{array}{l}\text { image Centroid } \\
\text { zone (ICZ), } \\
\text { zone centroid } \\
\text { zone (ZCZ) and } \\
\text { hybrid }\end{array}$ & $\begin{array}{ll}\text { SVM } & \\
\text { with } & \text { RBF } \\
\text { kernels } & \end{array}$ & 60,000 & 97.71 \\
\hline $\begin{array}{l}\text { Awaid } \\
\text { ah and } \\
\text { Mehm } \\
\text { oud } \\
2009 \\
\end{array}$ & $\begin{array}{l}\text { Handw } \\
\text { ritten }\end{array}$ & $\begin{array}{l}\text { edge curvature, } \\
\text { short strokes \& } \\
\text { concavities }\end{array}$ & HMM & 21,120 & 99 \\
\hline $\begin{array}{l}\text { Ahmad } \\
\text { and } \\
\text { Maen } \\
\end{array}$ & $\begin{array}{l}\text { Online } \\
\text { arabic }\end{array}$ & structural & Matching & 3000 & 95 \\
\hline $\begin{array}{l}\text { Das et } \\
\text { al. } \\
2012 \\
\end{array}$ & $\begin{array}{l}\text { Handw } \\
\text { ritten } \\
\text { Arabic } \\
\end{array}$ & $\begin{array}{l}\text { MCPA and } \\
\text { QTLR }\end{array}$ & SVM & 3000 & 99.10 \\
\hline $\begin{array}{l}\text { Lawal } \\
\text { et al. } \\
2010\end{array}$ & $\begin{array}{l}\text { Handw } \\
\text { ritten } \\
\text { Arabic }\end{array}$ & $\begin{array}{l}\text { Contour } \\
\text { points } \\
\text { chain codes } \\
\text { features }\end{array}$ & 99.03 & 21120 & 99.03 \\
\hline
\end{tabular}




\section{Conclusion}

In this paper, we present the complete review of offline as well as online numeral recognition and the comparison of various feature extraction method, classifiers, dataset and accuracies. This survey will provide a complete guidance to new readers and researchers in the field of numeral recognition system.

\section{Future Work}

In future, we aim to develop a system for recognition of digits for Urdu, Farsi and Arabic using a classifier or number of classifier and will compare the recognition rates of these languages with the state of the art digits recognition systems. We will also develop the MDLTSM for numerals recognition, which already achieved good accuracy rates for Urdu characters in [44-45].

\section{References}

[1] B. Al-Badr and S. A. Mahmoud, "Survey and Bibliography of Arabic Optical Text Recognition," Signal Processing, vol. 41, no. 1, pp. 49-77, 1995.

[2] E. Behjat, "Recognition of characters and shapes," MSc. Dissertation,Electrical Engineering Department, Sharif University of Technology, Tehran, Iran, 1975.

[3] D. B. Megherbi, S. M. Lodhi, and A. J. Boulenouar, "Fuzzy Logic Model based Technique with Application to Urdu Character Recognition," Proc. SPIE Appl. Artif. Neural Networks Image Process., vol. 3962, pp. 13-24, 2000.

[4] S. Hussain, "Urdu Nastalique Optical Character Recognizer." [Online]. Available: http://182.180.102.251:8080/ocr.

[5] S. Naz, K. Hayat, M. I. Razzak, M.W. Anwar, S. A. Madani, and S. U. Khan, "The optical character recognition of Urdu-like cursive scripts," Pattern Recognit., vol. 47, no. 3, pp. 1229-1248, 2013.

[6] "Arabic - Unicode Consortium." [Online]. Available: http://www.unicode.org/charts/PDF/U0600.pdf.

[7] U. Pal and A. Sarkar, "Recognition of printed Urdu script," in Proceedings of the Seventh International Conference on Document Analysis and Recognition (ICDAR 2003), 2003.

[8] I. Shamsher, Z. Ahmad, J. K. Orakzai, A. Adnan, "OCR for printed Urdu script using feed forward neural network," Proc. World Acad. Sci. Eng. Technol., vol. 23, pp. 172175, 2007.

[9] S. M. Bilal, A. K. Khan, K. Anam, and S. Zafar, "Numerals Recognition for Urdu Script," Curr. Trends Signal Process., vol. 1, no. 2-3, pp. 1-6, 2011.

[10] M. W. Sagheer, C. L. He, N. Nobile, and C. Y. Suen, "A New Large Urdu Database for Off-Line Handwriting Recognition," in Proceeedings of International Conference on Image Analysis and Processing (ICIAP'09), 2009, vol. 5716, no. 37, pp. 538-546.

[11] S. Basu, N. Das, R. Sarkar, M. Kundu, M. Nasipuri, and D. K. Basu, "A Novel Framework for Automatic Sorting of Postal Documents with Multi-Script Address Blocks," Pattern Recognit., vol. 43, no. 10, pp. 3507-3521, 2010.

[12] M. Yusuf and T. Haider, "Recognition of Handwritten Urdu Digits using Shape Context," in Proc. 8th International Multitopic IEEE Conference (INMIC'04), 2004, pp. 569-572.
[13] T. Haider and M. Yusuf, "Accelerated Recognition of Handwritten Urdu Digits using Shape Context based Gradual Pruning," in Proc. International Conference on Intelligent and Advanced Systems (ICIAS'07), 2007, pp. 601-604.

[14] M. I. Razzak, S. A. Hussain, A. Belaïd, M. Sher, and others, "Multi-font Numerals Recognition for Urdu Script based Languages," Int. J. Recent Trends Eng., 2009.

[15] S. Malik and S. A. Khan, "Urdu Online Handwriting Recognition," in Proc. IEEE Symposium on Emerging Technologies, 2005, pp. 27-31.

[16] R. Azad, F. Davami, and H. S. Boroujeni, "Recognition of Handwritten Farsi/Arabic Numerals Based on Robust Feature Set and K-NN Classifier," Int. J. Comput. Inf. Technol., vol. 1, no. 3, pp. 220-230, 2013.

[17] H. Salimi and D. Giveki, "Farsi/Arabic handwritten digit recognition based on ensemble of SVD classifiers and reliable multi-phase PSO combination rule," Int. J. Doc. Anal. Recognit., vol. 16, no. 4, pp. 371-386, 2013.

[18] E. Radwan, "Hybrid of Rough Neural Networks for Arabic / Farsi Handwriting Recognition," vol. 2, no. 2, pp. 39-47, 2013.

[19] Z. Shokoohi, A. M. Hormat, F. Mahmoudi, and H. Badalabadi, "Persian handwritten numeral recognition using Complex Neural Network and non-linear feature extraction," in First Iranian Conference on Pattern Recognition and Image Analysis (PRIA), 2013, pp. 1-5.

[20] H. Alvari, S. Mehdi, H. Fard, B. Salehi, S. M. H. Fard, and B. Salehi, "A Decision Tree Based Method to Classify Persian Handwritten Numerals by Extracting Some Simple Geometrical Features," Int. J. Comput. Theory Eng., vol. 5, no. 1, pp. 118-122, 2013.

[21] M. S. Azmi, M. F. Nasrudin, K. Omar, C. W. S. B. C. Ahmad, and K. W. M. Ghazali, "Exploiting features from triangle geometry for digit recognition," in Control, Decision and Information Technologies (CoDIT), 2013 International Conference on, 2013, pp. 876-880.

[22] M. S. Azmi, M. F. Nasrudin, K. Omar, and K. W. M. Ghazali, "Farsi/Arabic Digit Classification Using Triangle Based Model Features with Ranking Measures," Int. Conf. Image Inf. Process. (ICIIP 2012), vol. 46, no. Iciip, pp. 128-133, 2012.

[23] A. Nooraliei, "Persian handwritten digits recognition by using zoning and histogram projection," in AI \& Robotics and 5th RoboCup Iran Open International Symposium (RIOS), 3rd Joint Conference of, 2013, pp. 1-5.

[24] M. Ziaratban, K. Faez, and F. Faradji, "Language-based feature extraction using template-matching in Farsi/Arabic handwritten numeral recognition," in Document Analysis and Recognition, 2007. ICDAR 2007. Ninth International Conference on, 2007, vol. 1, pp. 297-301.

[25] C. L. Liu and C. Y. Suen, "A new benchmark on the recognition of handwritten Bangla and Farsi numeral characters," Pattern Recognit., vol. 42, no. 12, pp. 32873295, 2009.

[26] N. S. Behbahan, "A Method based on Decision Trees and Neural Network for Recognition of Farsi Handwritten Digits," no. 5, pp. 1-8, 2013.

[27] H. R. Boveiri, "Using Geometrical Central Moments and Fuzzy Min-Max Neural Network,” pp. 76-82, 2010.

[28] H. R. Boveiri, "Transformation-Invariant Classification of Persian Printed Digits," Int. J. Signal Process. Image Process. Pattern Recognit., vol. 4, no. 3, pp. 153-164, 2011.

[29] O. Rashnodi, "Using Box Approach in Persian Handwritten Digits Recognition," vol. 32, no. 3, pp. 1-8, 2011. 
[30] O. Rashnodi, H. Sajedi, and M. Saniee Abadeh, "Persian Handwritten Digit Recognition using Support Vector Machines," Int. J. Comput. Appl., vol. 29, no. 12, pp. 1-6, 2011.

[31] O. Rashnodi, H. Sajedi, and M. S. Abadeh, "Using Box Approach in Persian Handwritten Digits Recognition," Int. J. Comput. Appl., vol. 32(3), pp. 975-8887, 2011.

[32] S. Mohammad, "Optimizing Recognition System of Persian handwritten digits," vol. 1, no. 2, 2012.

[33] A. Roy, N. Das, R. Sarkar, S. Basu, M. Kundu, and M. Nasipuri, "An axiomatic fuzzy set theory based feature selection methodology for handwritten numeral recognition," in ICT and Critical Infrastructure: Proceedings of the 48th Annual Convention of Computer Society of India-Vol I, 2014, pp. 133-140.

[34] Z. Qing and X. He, "Feature Extraction and Filter in Handwritten Numeral Recognition," in Geo-Informatics in Resource Management and Sustainable Ecosystem, Springer, 2013, pp. 58-67.

[35] I. Ntroduction, "Printed and Handwritten Hindi/Arabic Numeral Recognition Using Centralized Moments," vol. 5, no. 3, pp. 140-144, 2014.

[36] S. a. Mahmoud, "Arabic (Indian) handwritten digits recognition using Gabor-based features," in International Conference on Innovations in Information Technology, 2008, pp. 683-687.

[37] S. Mahmoud, "Recognition of writer-independent off-line handwritten Arabic (Indian) numerals using hidden Markov models," Signal Processing, vol. 88, no. 4, pp. 844-857, 2008.

[38] G. Sinha, "Arabic numeral Recognition Using SVM Classifier," vol. 9359, no. 5, pp. 62-67, 2013.

[39] S. A. Mahmoud and S. M. Awaida, "Recognition of offline handwritten Arabic (Indian) numerals using multiscale features and support vector machines vs. hidden markov models," Arab. J. Sci. Eng., vol. 34, no. 2B, pp. 429-444, 2009.

[40] S. M. Awaidah and S. a. Mahmoud, "A multiple feature/resolution scheme to Arabic (Indian) numerals recognition using hidden Markov models," Signal Processing, vol. 89, no. 6, pp. 1176-1184, Jun. 2009.

[41] A. Ahmad and H. Maen, "Recognition of On-line Handwritten Arabic Digits Using Structural Features and Transition Network," vol. 32, pp. 275-281, 2008.

[42] N. Das, J. M. Reddy, R. Sarkar, S. Basu, M. Kundu, M. Nasipuri, and D. K. Basu, "A statistical-topological feature combination for recognition of handwritten numerals," Appl. Soft Comput., vol. 12, no. 8, pp. 2486-2495, Aug. 2012.

[43] I. a. Lawal, R. E. Abdel-Aal, and S. a. Mahmoud, "Recognition of handwritten Arabic (Indian) numerals using Freeman's chain codes and abductive network classifiers," Proc. - Int. Conf. Pattern Recognit., no. September 2015, pp. 1884-1887, 2010.

[44] S. Naz, A. I. Umar, R. Ahmad, S. B. Ahmed, S. H. Shirazi, M. I. Razzak, "Urdu Nasta'liq text recognition system based on multi-dimensional recurrent neural network and statistical features," Neural Computing and Applications,vol. 26, no. 8, pp. 1-13.

[45] S. Naz, A. I. Umar, R. Ahmad, S. B. Ahmed, S. H. Shirazi, I. Siddiqi and M. I. Razzak, "Offline Cursive UrduNastaliq Script Recognition using Multidimensional Recurrent Neural Networks," Neurocomputing, http://dx.doi.org/10.1016/j.neucom.2015.11.030. 